\title{
Adoption Level of Bi-voltine Silkworm Rearing Practices among Farmers of Chitradurga District, India
}

\author{
Imrankhan Jiragal*, M.V. Srinivasa Reddy, Mahinsharif, Mohankumar and R.G. Naik \\ Departmernt of Agricultural Extension, UAS, GKVK, Bengaluru and COS, \\ Chintamani, Karnataka, India \\ *Corresponding author
}

\section{A B S T R A C T}

\begin{tabular}{|c|c|}
\hline & Sericulture is an agro based industry providing lively hood to about seven million of rural \\
\hline $\begin{array}{l}\text { Ke y w or d s } \\
\text { Bi-voltine } \\
\text { Silkworm, } \\
\text { Sericulture }\end{array}$ & $\begin{array}{l}\text { adoption pattern and its level of profits obtained by adopting the hybrid variety of Bi- } \\
\text { voltine silkworm rearing in Karnataka are scanty Hence, owing to the increasing } \\
\text { importance of hybrid Bi-voltine silkworm rearing and its importance in rural areas, the }\end{array}$ \\
\hline Article Info & ine silkworm rearing practices and their personal, socio-economic characteristic of \\
\hline $\begin{array}{l}\text { Accepted: } \\
18 \text { January } 2019 \\
\text { Available Online: } \\
10 \text { February } 2019\end{array}$ & $\begin{array}{l}\text { sericulture farmers. The study was conducted in the year } 2017-2018 \text { in Molakalmuru, } \\
\text { Challakere and Hiriyur taluks of Chitradurga district in Karnataka. From this district } \\
\text { among the } 120 \text { respondents majority }(61.67 \%) \text { of the respondents of Bi-voltine silkworm } \\
\text { rearing farmers belong to high adoption category. Whereas, } 22.50 \text { and } 15.83 \text { per cent of } \\
\text { the respondents belong to medium and low adoption categories respectively. The }\end{array}$ \\
\hline & $\begin{array}{l}\text { relationship between Education, Mass media participation, Extension agency contact, and } \\
\text { Extension participation were found to have significant relationship at one per cent level of } \\
\text { significance. }\end{array}$ \\
\hline
\end{tabular}

\section{Introduction}

Sericulture is an agro based industry providing lively hood to about seven million of rural people in India. Sericulture provides immense employment potential for both men and women. Of the four major types of silks namely, Tasar, Eri and Muga produced in India, Mulberry silk occupies the major portion and mainly produced in the three southern states namely Karnataka, Andhra
Pradesh and Tamil Nadu and West Bengal in eastern part of the country. Because of new technology development and technology dissemination, number of modern sericulture activities is being implemented at the field level contributing to the higher silk output and in turn betterment of farmer's income.

Sericulture is ideally suited for improving the social and economic standards of the poor. India is the second largest producer of silk 
after China and biggest consumer of Raw silk and silk fabric. In India Karnataka stands first in area 20,89,447 ha and 2,85,233 M.T production. Bi-voltine silk production has been one of the priority sectors of Indian silk Industry to make sericulture a sustainable commercial activity by meeting the international silk standards, enhancing productivity and processing of cocoons rearing of $\mathrm{Bi}$-voltine silk worms plays a significant role but its production is yet to meet the targets.

Out of 16500 M.T of the country's total raw silk production, 14620 M.T was of the mulberry type, While, eri, muga and tasar silks accounted for $8.7,0.65$ and 1.9 per cent of total production respectively. The country has a monopoly in muga and is one of the leading producer of tasar silk in the world. Karnataka occupies the pride place in the sericulture map of India. Karnataka is known as the fables land of 'Sandal and silk', has more than 45.35 per cent of the total area under mulberry cultivation contributing over 44.25 per cent of silk produced in the country. Mulberry occupies an area of 91,491 hectares with a production of 9,8,222 M.T of raw silk. About 87 per cent in the states mulberry area and 93 per cent of its cocoon production is concentrated in traditional areas of Karnataka Mysore, Kolar, Chitradurga, Bangalore, Tumkur and Mandya districts.

For the development and success of any farm based activity, new technology development and its proper dissemination plays a major role. Since two to three decades, a good number of innovative and highly productive technologies have been developed by the scientists of both Central and State sector research institutes and many of them have reached the field successfully contributing for the success of sericulture. However, there is a lacuna in the technology dissemination and adoption of improved practices by the farmers. Hence, the present study is conducted to know the gap in the adoption of improved sericulture practices and the associated factors contributing for the success and failure of sericulture in Chitradurga district of Karnataka.

Studies on the adoption pattern and its level of profits obtained by adopting the hybrid variety of $\mathrm{Bi}$-voltine silkworm rearing in Karnataka are scanty. Hence, owing to the increasing importance of hybrid Bi-voltine silkworm rearing and its importance in rural areas, the present study was undertaken with the following specific objectives:. To study the extent of adoption of Mulberry cultivation and $\mathrm{Bi}$-voltine silkworm rearing practices and to know the association among socioeconomic, psychological and communication characteristics of farmers with their adoption level

\section{Materials and Methods}

The study was conducted during March-April 2018 and an Ex-post facto research design was followed to assess the Bi-voltine Silkworm rearing farmers. Chitradurga district was selected purposively owing to more area and production under Bi-voltine silkworm rearing and assured irrigation facility. Chitradurga district has six taluks, out of which Molakalmuru, Challakere and Hiriyur taluks were selected purposively for the study considering the higher area under Bi-voltine silkworm rearing practices.

\section{Results and Discussion}

With respect to the extent of adoption of recommended practices of mulberry cultivation of Bi-voltine silkworm rearing farmers, It could be observed from Table 1 that out of 120 farmers majority of Bi-voltine silkworm rearing farmers who had fully adopted mulberry cultivation practices like 
fertilizer $(90.00 \%)$, drip material $(89.16 \%)$, pruning $(87.50 \%)$, Bio-fertilizer $(87.50 \%)$, Weeding $(85.83 \%)$, growing of mulberry cuttings $(84.16 \%)$, and Plant protection $(83.33 \%)$ and Manure $(77.50 \%)$,.

A considerable percentage partially adopted were Manure $(22.50 \%)$, Mulberry cuttings $(15.83 \%)$, Plant protection (15.83\%), Weeding (13.33\%), Bio-fertilizer (12.50\%), Pruning (12.50\%), Fertilizer (10.00\%). Practices such as, drip material $(10.83 \%)$ and plant protection $(0.833 \%)$, weeding $(0.833 \%)$, of the farmers had not adopted mulberry cultivation practices. The reason for high adoption of mulberry cultivation is they have well contact with the extension worker and the reason for high adoption could be the educational status of the respondents was found to be significant. This would enable them to acquire better knowledge to practice of mulberry cultivation skillfully. Probable reasons for low adoption of these practices might be due to low extension contact and low extension participation, besides high input cost. The results were in accordance with the findings of Vijay Prakash and Dandin (2005).

\section{Extent of adoption of Bi-voltine silkworm rearing house standards}

Perusal of Table 2 shows that the Bi-voltine silkworm rearing farmers had fully adopted silkworm rearing house standards like Rearing bed (93.33\%), stand (93.33\%), Rearing plates $(92.50 \%)$, Sprayers $(92.50 \%)$ Chandrike (92.50\%), Sponge rubber $(92.50 \%)$ Uziflynet (91.66\%), Hygrometer (91.66\%), Ant wells (85.00\%), Gunny cloth (93.33\%), Cleaning net (89.16\%), Leaf choppers $(87.50$ $\%$ ), Chawki rearing boxes (87.50\%) Rearing house (86.66\%), and Bamboo baskets $(85.83 \%)$ respectively. The reason for high adoption could be the educational status of the respondents which would enable them to have a better knowledge to practice Bi-votine silkworm rearing house standards skillfully

A considerable percentage Ant wells (15.00 $\%)$, Bamboo baskets (14.16 \%), Rearing house $(13.33 \%)$, Leaf choppers $(12.50 \%)$, Chawki rearing boxes $(12.50 \%)$, Cleaning net $(10.83 \%)$, Uzi fly net $(8.33 \%)$, Hygrometer(8.33 \%), Sponge rubber (7.50 $\%)$, Rearing plates $(7.50 \%)$, Chandrike (7.50\%), Sprayers $(7.50 \%)$, Stand (6.66\%), Gunny cloth(6.66\%), Rearing bed (6.66\%), had not adopted in main house standards respectively. Probable reasons for nonadoption of these practices might be due to low extension contact and education, besides high input cost. The results are in agreement with the findings of Sharma et al., (1999)

\section{Adoption level of recommended cocoon production practices by Bi-voltine silkworm rearing farmers}

\section{Seeds/DFLs}

Perusal of Table 3 shows that the Bi-voltine silkworm rearing farmers had fully adopted production practices like DFLs (100.00\%), Disinfection of rearing house $(99.10 \%)$, Method of rearing $(97.50 \%)$, Method of bed cleaning $(97.50 \%)$, Method of picking of silkworms (99.16 \%), and Mountages (95.83 $\%)$ Hybrid silk worm (86.66\%), A considerable percentage 13.33 per cent of the farmers had not adopted Hybrid silk worm production practices. From the Table 3 Majority of the Bi-voltine silkworm rearing farmers had fully adopted rearing practices. The reason is due to high yield of hybrid Bivoltine cocoons compared to traditional varieties and the change agent's promotion for higher adoption of Bi-voltine silkworm rearing. In addition, majority of the respondents were belonging to literate education level that may be the reason for high adoption 


\section{Inputs used in silkworm rearing}

Inputs used in silkworm rearing indicated in the Table 3 revealed that the Bi-voltine silkworm rearing farmers had fully adopted practices like lime applications in silkworm $\operatorname{bed}(97.50 \%)$ and chemicals used in disinfection of rearing house $(90.00 \%)$. It is clear from Table 3 all most all the farmers had adopted lime application methods. The reason might be due to that the farmers were aware of these practices and majority of the farmers were practicing because the farmers were well known about using of those inputs.

\section{Pest management}

Bi-voltine silkworm rearing farmers had fully adopted the practice of management of Uzi fly $(98.33 \%)$ There was very less incidence of Uzi fly to Bi-voltine silkworm rearing might be the reason for high adoption and proper preventive measure were taken.

Table.1 Extent of adoption of recommended practices in mulberry cultivation

\begin{tabular}{|c|l|c|c|c|c|c|c|}
\hline Sl. No. & Recommended & \multicolumn{2}{|c|}{ Full Adoption } & \multicolumn{2}{c|}{ Partial Adoption } & \multicolumn{2}{c|}{ Non Adoption } \\
\cline { 3 - 8 } & cultivation practices & No. & \% & No. & \% & No. & \% \\
\hline $\mathbf{1}$ & Cuttings & 101 & 84.16 & 19 & 15.83 & 0 & 0.00 \\
\hline $\mathbf{2}$ & Manure (FYM) & 93 & 77.50 & 27 & 22.50 & 0 & 0.00 \\
\hline $\mathbf{3}$ & Fertilizer & 108 & 90.00 & 12 & 10.00 & 0 & 0.00 \\
\hline $\mathbf{4}$ & Bio-Fertilizer & 105 & 87.50 & 15 & 12.50 & 0 & 0.00 \\
\hline $\mathbf{5}$ & Drip Material & 107 & 89.16 & 0 & 0.00 & 13 & 10.83 \\
\hline $\mathbf{6}$ & Weeding & 103 & 85.83 & 16 & 13.33 & 1 & 0.83 \\
\hline $\mathbf{7}$ & Pruning & 105 & 87.50 & 15 & 12.50 & 0 & 0.00 \\
\hline $\mathbf{8}$ & Plant protection & 100 & 83.33 & 19 & 15.83 & 1 & 0.83 \\
\hline
\end{tabular}

Table.2 Extent of adoption of Bi-voltine silkworm rearing house standards

\begin{tabular}{|c|l|c|c|c|c|}
\hline \multicolumn{2}{|c|}{ Sl. } & \multicolumn{1}{|c}{ Items } & \multicolumn{2}{|c|}{ Adoption } & \multicolumn{2}{c|}{ NonAdoption } \\
\cline { 3 - 6 } No. & & No. & \% & No. & $\%$ \\
\hline $\mathbf{1}$ & Rearing house & 104 & 86.66 & 16 & 13.33 \\
\hline $\mathbf{2}$ & Rearing bed & 112 & 93.33 & 8 & 6.66 \\
\hline $\mathbf{3}$ & Chawki rearing boxes & 105 & 87.50 & 15 & 12.50 \\
\hline $\mathbf{4}$ & Rearing plates & 111 & 92.50 & 9 & 7.50 \\
\hline $\mathbf{5}$ & Chandrike & 111 & 92.50 & 9 & 7.50 \\
\hline $\mathbf{6}$ & Stand & 112 & 93.33 & 8 & 6.66 \\
\hline $\mathbf{7}$ & Cleaning net & 107 & 89.16 & 13 & 10.83 \\
\hline $\mathbf{8}$ & Uzi fly net & 110 & 91.66 & 10 & 8.33 \\
\hline $\mathbf{9}$ & Hygrometer & 110 & 91.66 & 10 & 8.33 \\
\hline $\mathbf{1 0}$ & Sponge rubber & 111 & 92.50 & 9 & 7.50 \\
\hline $\mathbf{1 1}$ & Ant wells & 102 & 85.00 & 18 & 15.00 \\
\hline $\mathbf{1 2}$ & Gunny cloth & 112 & 93.33 & 8 & 6.66 \\
\hline $\mathbf{1 3}$ & Leaf choppers & 105 & 87.50 & 15 & 12.50 \\
\hline $\mathbf{1 4}$ & Sprayer & 111 & 92.50 & 9 & 7.50 \\
\hline $\mathbf{1 5}$ & Bamboo baskets & 103 & 85.83 & 17 & 14.16 \\
\hline
\end{tabular}


Table.3 Adoption level of recommended cocoon production practices by Bi-voltine silkworm rearing farmers

\begin{tabular}{|c|c|c|c|c|c|c|c|}
\hline \multirow[t]{2}{*}{$\begin{array}{l}\text { Sl. } \\
\text { No }\end{array}$} & \multirow[t]{2}{*}{ Items } & \multicolumn{2}{|c|}{ Full Adoption } & \multicolumn{2}{|c|}{$\begin{array}{c}\text { Partial } \\
\text { Adoption }\end{array}$} & \multicolumn{2}{|c|}{ NonAdoption } \\
\hline & & No. & $\%$ & No. & $\%$ & No. & $\%$ \\
\hline \multicolumn{8}{|c|}{ A. $\quad$ Seeds /DFLs } \\
\hline 1 & Hybrid Silk worm (FC1XFC2) & 104 & 86.66 & 0 & 0.00 & 16 & 13.33 \\
\hline 2 & DFLs & 100 & 100 & 0 & 0.00 & 0 & 0.00 \\
\hline 3 & Disinfection of rearing house & 120 & 99.10 & 0 & 0.00 & 0 & 0.00 \\
\hline 4 & Method of rearing (Shoot rearing) & 117 & 97.5 & 3 & 2.50 & 0 & 0.00 \\
\hline 5 & $\begin{array}{l}\text { Method of bed cleaning(Using Net/ } \\
\text { Conventional method) }\end{array}$ & 117 & 97.5 & 3 & 2.50 & 0 & 0.00 \\
\hline 6 & $\begin{array}{l}\text { Method of picking of silkworms } \\
\text { (Using Net/Hand) }\end{array}$ & 119 & 99.16 & 1 & 0.83 & 0 & 0.00 \\
\hline 7 & $\begin{array}{l}\text { Mountages(Rotary/Bamboo } \\
\text { mountages) }\end{array}$ & 115 & 95.83 & 5 & 4.16 & 0 & 0.00 \\
\hline \multicolumn{8}{|c|}{ B. Inputs used in silkworm rearing } \\
\hline 8 & Lime application in Silkworm bed & 117 & 97.50 & 3 & 2.50 & 0 & 0.00 \\
\hline 9 & $\begin{array}{l}\text { Chemicals used in Disinfection of } \\
\text { rearing house }\end{array}$ & 108 & 90.00 & $\begin{array}{l}1 \\
1\end{array}$ & 9.16 & 1 & 0.83 \\
\hline \multicolumn{8}{|c|}{ C. Pest management } \\
\hline 10 & Use of Uzi traps technology & 118 & 98.33 & 2 & 1.66 & 0 & 0.00 \\
\hline \multicolumn{8}{|c|}{ D. Disease management } \\
\hline 11 & Flacherry disease management & 116 & 96.66 & 0 & 0.00 & 4 & 3.33 \\
\hline 12 & Grocessory disease management & 120 & 98.00 & 0 & 0.00 & 0 & 0.00 \\
\hline 13 & Muscardine disease management & 113 & 94.16 & 0 & 0.00 & 7 & 5.83 \\
\hline \multicolumn{8}{|c|}{ E. Cocoon harvest and post - harvest management } \\
\hline 14 & Time of Harvesting of cocoons & 116 & 96.66 & 4 & 3.33 & 0 & 0.00 \\
\hline 15 & Manual Harvesting & 100 & 100 & 0 & 0.00 & 0 & 0.00 \\
\hline 16 & Transportation of cocoons & 100 & 100 & 0 & 0.00 & 0 & 0.00 \\
\hline 17 & Marketing of cocoons & 100 & 100 & 0 & 0.00 & 0 & 0.00 \\
\hline
\end{tabular}

Table.4 Adoption level of recommended practices for DFLs by Bi-voltine silkworm rearing farmers

\begin{tabular}{|c|l|c|c|c|c|c|c|}
\hline \multicolumn{1}{|c|}{ SI. } & \multicolumn{1}{|c|}{ Items } & \multicolumn{2}{c|}{ Full Adoption } & \multicolumn{2}{c|}{ Partial Adoption } & \multicolumn{2}{c|}{ Non Adoption } \\
\cline { 2 - 8 } No. & & No. & $\mathbf{\%}$ & No. & $\%$ & No. & $\%$ \\
\hline $\mathbf{1}$ & DFLs & 100 & 83.30 & 0 & 0.00 & 20 & 16.67 \\
\hline $\mathbf{2}$ & Formalin & 116 & 96.66 & 4 & 3.33 & 0 & 0.00 \\
\hline $\mathbf{3}$ & Lime dust & 119 & 99.16 & 1 & 0.83 & 0 & 0.00 \\
\hline $\mathbf{4}$ & Bleaching powder & 108 & 90.00 & 12 & 10.00 & 0 & 0.00 \\
\hline $\mathbf{5}$ & Disease control measures & 116 & 96.66 & 4 & 3.33 & 0 & 0.00 \\
\hline $\mathbf{6}$ & Paraffin paper & 119 & 99.16 & 1 & 0.83 & 0 & 0.00 \\
\hline
\end{tabular}


Table.5 Over all Adoption level of Bi-voltine silkworm rearing farmers in Chitradurga, district

\begin{tabular}{|c|c|c|}
\hline Category & No. & Percentage \\
\hline Low (<98.53) & 19 & 15.83 \\
\hline Medium (98.53-103.11) & 27 & 22.50 \\
\hline High (>103.11) & 74 & 61.67 \\
\hline
\end{tabular}

Table.6 Relationship between adoption levels of Bi-voltine silkworm rearing farmers with the independent variables

\begin{tabular}{|c|c|c|}
\hline Sl. No. & Characteristics & Correlation coefficient \\
\hline 1 & Age & $0.0375^{\mathrm{NS}}$ \\
\hline 2 & Education & $0.2666^{* *}$ \\
\hline 3 & Annual income & $0.2111^{*}$ \\
\hline 4 & Size of family & $0.0573^{\mathrm{NS}}$ \\
\hline 5 & Attitude towards sericulture & $0.1999 *$ \\
\hline 6 & Innovativeness & $0.2442 *$ \\
\hline 7 & Achievement motivation & $0.2120 *$ \\
\hline 8 & Scientific orientation & $0.2490 *$ \\
\hline 9 & Economic motivation & $0.2001 *$ \\
\hline 10 & Risk orientation & $0.0734^{\mathrm{NS}}$ \\
\hline 11 & Social participation & $0.0167 *$ \\
\hline 12 & Mass media participation & $0.2768 * *$ \\
\hline 13 & Extension agency contact & $0.3122 * *$ \\
\hline 14 & Extension participation & $0.2999 * *$ \\
\hline
\end{tabular}

\section{Disease management}

Bi-voltine silkworm rearing farmers had fully adopted disease management practices like, grocessory disease $(98.00 \%)$, flachery $(96.66 \%)$, and muscardine disease $(93.33 \%)$ of the Bi-voltine silkworm rearing farmers. The possible reason was that since they felt that less incidence of disease to $\mathrm{Bi}$ voltine silkworm rearing and probable reason for this might be that proper preventive measure had taken.

\section{Cocoon harvest and post - harvest management}

Cent percent of the farmers had fully adopted manual harvesting, transportation and marketing of cocoons and time of harvesting (96.66\%).All most all the Bi-voltine silkworm rearing farmers had adopted post-harvest management practices. The reason is due to farmers had good knowledge regarding harvest and post-harvest practices like correct time of harvesting, storing, time of selling and majority of the respondents were literate education level that might be the reason.

Table 4 reveals that, followed by lime dust $(99.16 \%)$, paraffin paper $(99.16 \%)$ formalin (96.66 \%), disease control measures (96.66\% bleaching powder $(90.00 \%)$,), and had fully adopted. $83.30 \%$ of the farmers had full adopted of DFLs. Whereas, DFLs (16.67\%) of the farmers were not adopted. The reason 
might be majority of $\mathrm{Bi}$-voltine farmers were well educated category. Overall adoption level of Bi-voltine silkworm rearing farmers with respect to recommended cultivation practices. The results presented in Table 5, shows that majority (61.67\%) of Bi-voltine silkworm rearing farmers belongs to high adoption category. Whereas, 22.50 and 15.83 per cent of the respondents belongs to medium and low adoption categories, respectively.

The relationship between adoption levels of Bi-voltine silkworm rearing farmers with the independent variables

The relationship between Education, Mass media participation, Extension agency contact, and Extension participation were found to have significant relationship with their Adoption level at one per cent level of significance. Whereas, the Annual income, Attitude towards sericulture, Innovativeness, Achievement motivation, Scientific orientation, Economic motivation, and Social participation were found to be significant at five per cent level of significance with adoption level. The remaining variables such as Age, Size of family, and Risk orientation had non-significant association with adoption level (Table 6).

In conclusion, the study was conducted during March-April 2018 in Chitradurga district. Molakalmuru, Challakere, and Hiriyur taluks were selected considering the highest area under hybrid Bi-voltine silkworm rearing practices. The results revealed that Majority $(61.67 \%)$ of the respondents of Bi-voltine silkworm rearing farmers belong to high adoption category. Whereas, 22.50 and 15.83 per cent of the respondents belong to medium and low adoption categories respectively. The relationship between Education, Mass media participation, Extension agency contact, and Extension participation were found to have significant relationship with their Adoption level at one per cent level of significance. Whereas, the Annual income, Attitude towards sericulture, Innovativeness, Achievement motivation, Scientific orientation, Economic motivation, and Social participation were found to be significant at five per cent level of significance with their adoption level of sericulture farmers.

\section{References}

Jayaram, H. and Indumati, S. 2010. Awareness, attitude and adoption of technological practices in sericulture A discriminant function analysis. Indian Journal of Sericulture, 49(1): 64-69.

Lakshmanan, S., Mallikarjuna, B., Ganapathy Rao, R. Jayaram, H. and Geetha Devi, R.G. 1998. Studies on adoption of sericultural innovations at farmers level in Tamil Nadu: An empirical analysis. Indian Journal of Sericulture 37(1): 4447.

Mallikarjuna, B., Munikrishnappa, H. M. and Vijayaprakash, N. B. 2009. Studies on constraints in the adoption of new technologies in mulberry cultivation and silkworm rearing under irrigated conditions. Indian J. Sericulture, 43 (2): 216-218.

Quadri, F.I.S., Malik, M.A., Auqib Sabhat and Firdose Ahamd Malik, 2010. Adoption of improved sericultural practices by sericulturists in border areas of Kashmir. Int. J. Agriculturee. Stat. Seri.6(1): 197-201.

Rogers, E., and Shoemaker, F., 1971, Communication of innovations: A cross-cultural approach. New York, NY: The Free Press department of Michigan state university, east lansing, MI, P; 476

Sharma, P.C., Kumaresan, P. and Malikarjunappa, H.M. 1999. Adoption of improved reeling technologies in 
traditional areas - A study in Chamarajanagar district Karnataka. Indian Journal of Sericultrue, 38(2): 8388.

Sreenivas, B. T., Umesha, A., Himantharaj, M. T., Jaishankar, Qadri, S. M. H. and Kamble, C. K. 2009. Impact of IVLP on Mulberry leaf and cocoon Yield at
Farmers level. Journal of Agri. Extn. Management. 10 (2): 93-98.

Vijaya Prakash, N.B. and Dandin, S.B. 2005. Factors influencing the adoption of bivoltine sericultural practices in Mandya district of Karnataka. Indian Journal of Sericulture 44(1): 55-58

\section{How to cite this article:}

Imrankhan Jiragal, M.V. Srinivasa Reddy, Mahinsharif, Mohankumar and Naik, R.G. 2019. Adoption Level of Bi-voltine Silkworm Rearing Practices among Farmers of Chitradurga District. Int.J.Curr.Microbiol.App.Sci. 8(02): 2481-2488.

doi: https://doi.org/10.20546/ijcmas.2019.802.288 